\title{
Small intestine dysfunction in Parkinson's disease
}

\author{
Justyna Dutkiewicz $^{1} \cdot$ Stanisław Szlufik $^{1} \cdot$ Michał Nieciecki $^{2} \cdot$ Ingeborga Charzyńska $^{2} \cdot$ \\ Leszek Królicki $^{2} \cdot$ Piotr Smektała $^{3} \cdot$ Andrzej Friedman $^{1}$
}

Received: 12 March 2015/ Accepted: 6 August 2015/Published online: 26 August 2015

(c) The Author(s) 2015. This article is published with open access at Springerlink.com

\begin{abstract}
The aim of this study was to assess the small bowel transit time in patients with Parkinson's disease (PD). Ten patients with PD with no gastrointestinal complaints and ten healthy control subjects were investigated using single photon emission computed tomography fused with computed tomography after swallowing of a specially prepared capsule containing technetium $99 \mathrm{~m}$, which allowed visualization of the passage in the intestines. Preliminary results show that the small intestine passage in PD patients was prolonged compared to controls.
\end{abstract}

Keywords Parkinson's disease · Small intestine passage · Autonomic dysfunction

\section{Introduction}

Parkinson's disease (PD) is one of the most common neurodegenerative disorders. It is characterized by resting tremor, rigidity, bradykinesia and postural instability. Motor symptoms are usually accompanied by non-motor ones including symptoms from the gastrointestinal tract. Constipation was already described by James Parkinson (1817).

Justyna Dutkiewicz

justyna_dutkiewicz@wp.pl

1 Department of Neurology, Faculty of Heath Science, Medical University of Warsaw, ul. Kondratowicza 8, 03-242 Warsaw, Poland

2 Department of Diagnostic Imaging, Mazovian Brodno Hospital in Warsaw, ul. Kondratowicza 8, 03-242 Warsaw, Poland

3 Faculty of Materials Science and Engineering, Warsaw University of Technology, ul. Woloska 141, 02-507 Warsaw, Poland
Gastrointestinal dysfunction is the most common non-motor symptom observed in PD with constipation being the most prevalent, often preceding the motor symptoms (Edward et al. 1992; Berrios et al. 1995; Goldman and Postuma 2014; Krygowska-Wajs et al. 2000). Constipation is five times more common in patients with PD than in general population (Albanese et al. 1997). Defecatory anorectal dysfunctions were found in more than $60 \%$ patients with PD (Edward et al. 1991; Cersosimo and Benarroch 2012). Gastrointestinal symptoms in PD were studied extensively but were aimed mostly on dysphagia, gastric emptying and constipation. Decreased dysphagia limit, prolongation of lower esophageal phase of swallowing and prolongation of laryngeal movement were found in PD patients (Potulska et al. 2003). Gastric emptying delay was detected long time ago (Krygowska-Wajs et al. 2009). Despite all these observations to the best of our knowledge, the function of small intestine was not studied in PD. In the literature, several methods for assessment of the small intestine transit time can be found, such as breath stable-isotope small bowel transit time, radiopaque marker small bowel transit time, breath hydrogen test, inulin or lactulose breath test, small intestine scintigraphy. Small bowel transit time can be also measured with wireless motility capsule (Lawrence et al. 2012). Unfortunately, indigestible solid particles such as the radiopaque markers and wireless motility capsule may not move through the gastrointestinal tract in the same manner as a physiologic meal (Madsen et al. 1991). For breath test methods, the oro-cecal transit time can be misassessed in patients with gastroparesis (Lawrence et al. 2012). The aim of this study was to investigate dynamic of small intestine transport using single photon emission computed tomography fused with computed tomography (SPECT/CT) examination in patients with Parkinson disease, who had to swallow a small size capsule filled with 
radioisotope. The use of human subjects was carried out with adequate understanding and written consent of the subjects. This study was approved by the Ethics Committee of the Medical University of Warsaw.

\section{Materials and methods}

Ten patients with Parkinson's disease lasting for 6-12 years fulfilling international criteria of the diagnosis, at the ages ranging from 45 to 70 , of both sexes ( 6 females and 4 males), with no gastrointestinal complaints, treated with levodopa only (average daily dose $965 \pm 295 \mathrm{mg}$ ) were studied and compared to ten control age and sexmatched subjects (more details in Table 1). Patients from control group were hospitalized in our clinic for other reasons than Parkinson's disease. Subjects in both groups were not receiving drugs that might affect the motility of the gastrointestinal tract. The PD patients were not receiving any antiparkinsonian medication starting $12 \mathrm{~h}$ before the swallow until the end of the study. The capsule containing the isotope ${ }^{99 \mathrm{~m}} \mathrm{Tc}$-colloid, which was able to pass through the whole gut without disintegration (Fig. 1) was swallowed in the morning on empty stomach and

Table 1 Data of patients

\begin{tabular}{lll}
\hline & PD group & Control group \\
\hline Number & 10 & 10 \\
Sex F/M & $6 / 4$ & $4 / 6$ \\
Age (years \pm SD) & $60 \pm 8.4$ & $60 \pm 8.6$ \\
Levodopa mg (daily dose \pm SD) & $965 \pm 295$ & Without \\
Drugs that may affect the motility of the gastrointestinal tract & Without & Without \\
\hline
\end{tabular}

Fig. 1 The capsule used in this experiment

Fig. 2 Typical picture of the fusion of SPECT and CT in PD and control subjects after 2 and $24 \mathrm{~h}$ after the intake of the capsule containing the isotope

\section{The outside part of capsule}

Active carbon

The filling of capsule by polymer Eudragit $S$ The inside part of capsule

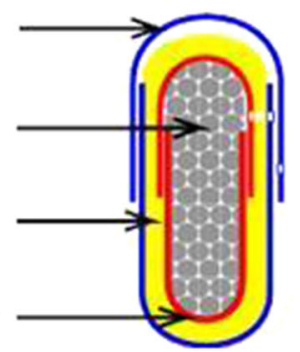

Ready capsule with the isotope solution inside

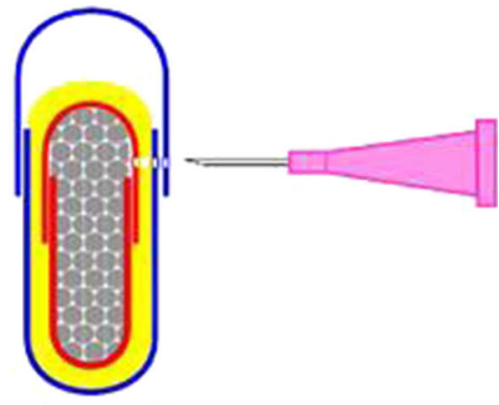

"Open" capsule ready to filling by using the syringe

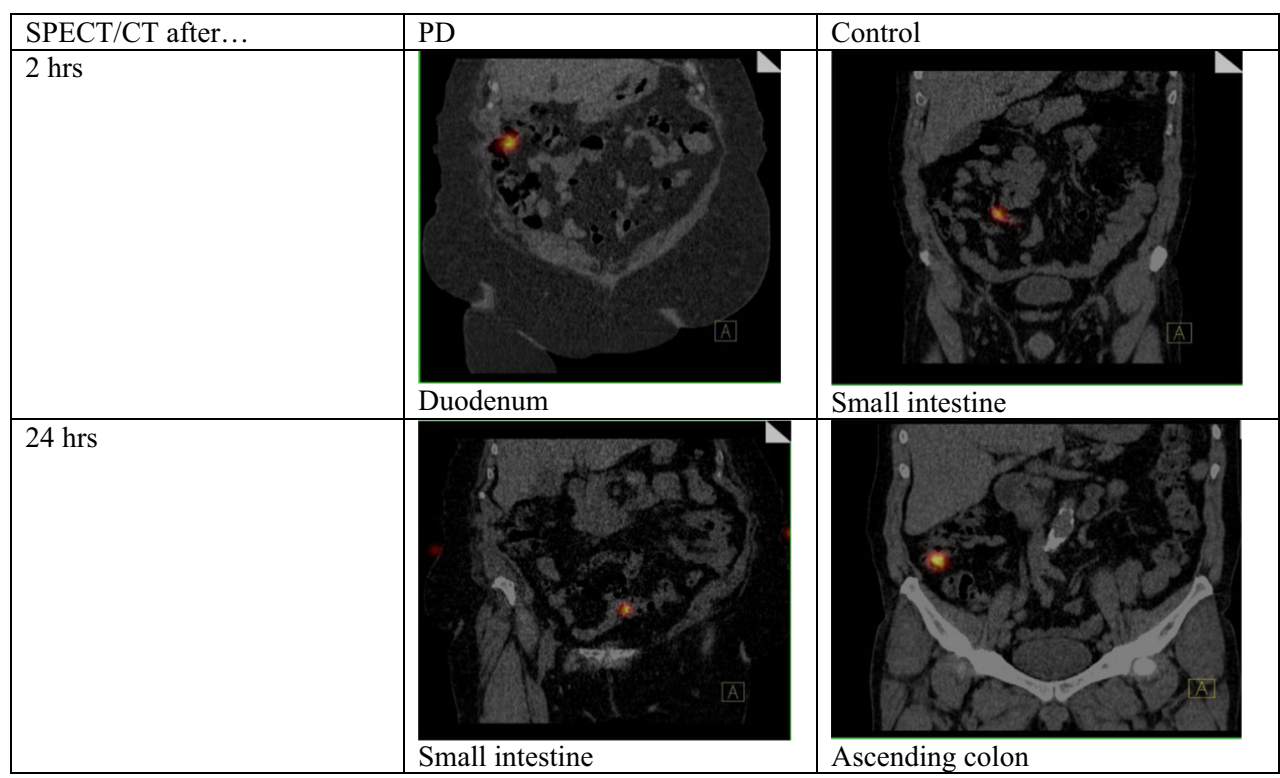


during the day on which the tests were performed all subjects had regular meals prepared in the hospital. Single photon emission computed tomography (SPECT) and computed tomography (CT) images obtained 2, 4, 6, 8 and $24 \mathrm{~h}$ after intake of the capsule were fused. The fusion of SPECT and CT is shown in Fig. 2.

\section{Results}

The appearance of the capsule in small intestine was delayed in PD patients compared to control as it was present in this segment of the gut already after $2 \mathrm{~h}$ after the intake in five controls and only in 2 PD patients. In all control subjects, the capsule left small intestine within $4 \mathrm{~h}$. In seven PD patients, the capsule was present in the small intestine for longer than $4 \mathrm{~h}$ being seen in one case also after $24 \mathrm{~h}$. This last difference is statistically significant $(p<0.01)$ as determined by $\chi^{2}$ test.

\section{Discussion}

Most of the methods for the examination of small bowel transit time are expensive, time-consuming, and what is most important have not gained widespread use because of the lack of standardized methods for the studies. It is not known if prolongation of oro-cecal transit time is due only to dysfunction in upper part of gastrointestinal system and large bowel or if a dysfunction of small bowel plays a role in this. Some researches deduced that prolongation of the oropharyngeal transit time is caused by rigidity and hypokinesia, and these symptoms affect the motor function of the tongue (Bushmann et al. 1989). The mechanism of swallowing disorders in PD may be the result of degeneration of the dorsal nucleus of the vagal nerve and esophageal myenteric plexus (Wakabayashi and Takahashi 1997). Pouclet et al. (2012) suggest that the Lewy pathology in gastrointestinal tract in PD patients is the cause of the elongated transit time. Our study has shown that elongation of the oro-cecal transit time in patients with Parkinson's disease may be related not only to the dysfunction of the upper gastrointestinal tract and colon, but also to the small intestine dysfunction. The data obtained from the study give physicians a different perspective on the problem of constipation in PD.

In conclusion, our preliminary results show that in $\mathrm{PD}$ there is a slowing down of the small intestine passage even in patients without any gastrointestinal clinical symptoms. This finding could influence the treatment of constipation in PD.

\section{Compliance with ethical standards}

Conflict of interest All authors declare no conflict of interest.

Open Access This article is distributed under the terms of the Creative Commons Attribution 4.0 International License (http://crea tivecommons.org/licenses/by/4.0/), which permits unrestricted use, distribution, and reproduction in any medium, provided you give appropriate credit to the original author(s) and the source, provide a link to the Creative Commons license, and indicate if changes were made.

\section{References}

Albanese A, Maria G, Bentivoglio AR, Brisinda G, Cassetta E, Tonali $P$ (1997) Botulinum toxin in the treatment of chronic constipation in Parkinson's disease. Eur J Neurol 4:S81-S83

Berrios G, Campbell C, Politynska B (1995) Autonomic failure, depression and anxiety in Parkinson's disease. Br J Psychiatry 166:789-792

Bushmann M, Dobmeyer SM, Leeker L, Perlmutter JS (1989) Swallowing abnormalities and their response to treatment in Parkinson's disease. Neurology 39:1309-1314

Cersosimo MG, Benarroch EE (2012) Pathological correlates of gastrointestinal dysfunction in Parkinson's disease. Neurobiol Dis 46:559-564

Edward LL, Pfeiffer RF, Quigley EM, Hofman R, Balluff M (1991) Gastrointestinal symptoms in Parkinson's disease. Mov Disord 6:151-156

Edward LL, Quigley EM, Pfeiffer RF (1992) Gastrointestinal dysfunction in Parkinson's disease: frequency and pathophysiology. Neurology 42:726-732

Goldman JG, Postuma R (2014) Premotor and nonmotor features of Parkinson's disease. Curr Opin Neurol 27:434-441

Krygowska-Wajs A, Lorens K, Thor P, Szczudlik A, Konturek S (2000) Gastric electromechanical dysfunction in Parkinson's disease. Funct Neurol 15:41-46

Krygowska-Wajs A, Cheshire WP Jr, Wszolek ZK, HubalewskaDydejczyk A, Jasinska-Myga B, Farrer MJ, Moskala M, SowaStaszczak A (2009) Evaluation of gastric emptying in familial and sporadic Parkinson disease. Parkinsonism Relat Disord 15:692-696

Madsen JL, Larsen N, Hilsted J, Worning H (1991) Scintigraphic determination of gastrointestinal transit times: a comparison with breath hydrogen and radiologic methods. Scand J Gastroenterol 26:1263-1271

Parkinson J (1817) An essay on the shaking palsy. Sherwood, Neely and Jones, London

Potulska A, Friedman A, Królicki L, Spychala A (2003) Swallowing disorders in Parkinson's disease. Parkinsonism Relat Disord 9:349-353

Pouclet H, Lebouvier T, Coron E, Neunlist M, Derkinderen P (2012) Lewy pathology in gastric and duodenal biopsies in Parkinson's disease. Mov Disord 27:708

Szarka LA, Camilleri M (2012) Methods for the assessment of small bowel transit. Semin Nucl Med 42:113-123

Wakabayashi K, Takahashi H (1997) Neuropathology of autonomic nervous system in Parkinson's disease. Eur Neurol 38(suppl. 2):2-7 